\section{A clinical ethics committee in a small health service trust}

SIR

Clinical ethics committees (CECs) in Britain increase in number despite uncertainty over remit, structure, and manner of working. 'Important functions fall outside the casework which intuitively forms the core of their activities $^{2}$ so benefits of a CEC for a small health care institution may be doubted if patient and staff numbers and therefore assumed frequency of case ethical dilemmas determine whether a committee is established. Small institutions are doubtless at no less risk of unethical practice. We report a survey of a CEC established in a small National Health Service (NHS) Trust in north-east Scotland comprising a district general hospital of 242 beds, GP-led community hospitals, and community and mental health services. Twenty-nine consultants and 1,100 other staff provide medical, surgical, paediatric, psychiatric and other services to a population of approximately 86,000 .

The CEC was established in the autumn of 1996 with the remit to provide a forum for the discussion of ethically troubling cases; to promote general clinical and research ethical discussion and education; to help develop ethically sound trust policies, and to contribute more generally to staff support. All senior clinical staff were informed by memo of the committee's existence, and the referral mechanism. Referral by patients and relatives was not offered. It was made clear that the CEC would only offer facilitation of discussion, not take binding decisions affecting patient care.

The facilitator (KW) invited a senior nurse, a psychotherapist, a paediatrician, a junior doctor, and most recently a practice development nurse to join him as members of the committee. Neither fixed terms of membership nor elections were planned. No votes in committee were to be held; it was not minuted though agreed revisions of draft policies were returned to the submitting party.

After 18 months the CEC's work was reviewed: questionnaires about knowledge of the CEC and their attitudes towards it were circulated to all consultants, senior house officers, ward managers and two unselected staff nurses from each ward and community hospital.
One case was referred; its urgency meant that a response was given by the facilitator alone, who spoke to clinicians and family and entered his views in the case notes. Guidelines-on patient possession of illicit drugs; cardiopulmonary resuscitation after collapse, and other forms of resuscitation -were commented on and redrafted; a further set on confidentiality were considered individually by members to expedite the response. An open meeting was held to permit discussion of questions from the floor by an invited panel consisting of a clergyman, a senior nurse manager, a consultant physician and a director of public health (more than forty people attended). Teaching sessions were held for medical students and junior doctors working in obstetrics; many informal comments were made about potential research projects.

Eighty-nine staff responded to 136 questionnaires. Only $54 \%$ knew of the CEC's existence, and $17 \%$ how to refer a case; $78 \%$ would take clinical ethical problems to a colleague but only $24 \%$ would refer to the CEC, whose most favoured role was education $(84 \%)$, with $81 \%$ considering case discussions valuable and $58 \%$ the refinement of policies. Sixty-five per cent of respondents wished the CEC to be elected but only $46 \%$ were willing to serve; $89 \%$ were happy to have their own patients' cases considered. Few felt that patient-clinician relations $(6 \%)$ or clinician autonomy $(9 \%)$ would be harmed. A quarter felt a health care ethics consultant would be beneficial.

Nursing and medical staff differed over whether patients should be told their case was to be discussed: $30 \%$ of consultants but $70 \%$ of nurses favoured this.

In common with CECs elsewhere ${ }^{3}$ casework was a small part of the workload. We feel that CECs wishing to address this work must keep a high profile within clinician groups: elections may help achieve this, giving an accountability that clinicians seem to want. Our experience suggests that nurses and doctors wish mainly education and support from CECs to facilitate the tackling of ethical dilemmas in their peer group. Involvement of patients and their representatives in resolving such problems is likely to remain contentious, though a CEC is not felt to be a threat to clinicianpatient relationships or clinician autonomy.

\section{References}

1 Gillon R. Clinical ethics committee pros and cons. Fournal of Medical Ethits 1997;23:203-4.

2 Fleetwood JE, Arnold RM, Baron $\overline{\mathrm{BJ}}$ Giving answers or raising questions? the problematic role of institutio ethics committees. Fournal of Medīanl Ethics 1989;15:137-42.

3 Thornton JG, Lilford RJ. Cliniol ethics committee. British Medical foownal 311:667-9.

KENNETH A WOOD MB, CHB, MST्ब, MRCPSYCI

SUSAN ELLIS MB, CI $\overrightarrow{\mathrm{HB}}$

Consultant Psychiatrist and Senior Ho\&se Officer, respectiv $y$

Dr Gray's Hospital, Elgin, Moray, Scotld $\mathrm{Ad}$ IV30 1 SA

\section{The recruitment of non-English speakingi subjects into human research G

SIR

Researchers now accept that ethies committees will only grant approve for research in which it can be shovif that all subjects are giving inforined consent. Not all researchers appes have taken this on board; many subm protocols suggesting that the $\mathrm{r} / \mathrm{F}$ searcher at the coalface will expla the pertinent facts to the prospectig subject, in mime, gesture, written spoken word and the committee co grant approval on this basis. The fact that the committee cannot be satisfied that informed consent will be obtained in every case is a matter of de concern.

This highlights a troublesome eth cal issue, namely the recruitment members of non-English speakin groups, including the so-called "et nic minority" groups into research studies. The question at the heart of this debate is whether it is ethical recruit members of any group int research when these subjects are not or cannot be, offered comprehensive information about the researchers intention, and the inherent risks and discomfort to which they will bo exposed by taking part. In cases where verbal consent is sought, it is a matter of argument whether a committe should be persuaded that researchers with an interest in the success of project should be allowed to recrui any subjects without complete rease surance that they will not coerce of mislead people into cooperating.

We insist that patient information leaflets and consent forms intended for use by English-speaking, English- 
reading subjects adhere to strict guidelines and, if they do not, we withhold approval until the matter is remedied. Those arguing for a different approach in other cases cite American literature, which documents the fact that ethnic minorities and the elderly may be underrepresented in clinical research. ${ }^{1}$ Such groups are deemed difficult to recruit for reasons that are not always clearly outlined by those failing to recruit them. In such cases one could conclude that beneficial innovations and advances could not be generalised to groups who have been excluded from trials and that they are therefore ultimately disadvantaged.

In circumstances where a subject cannot comprehend English or any language it may be unethical to include this person in research because of the value we place on the need for informed consent. The difficulties faced by research ethics committees are compounded by the problems of evaluating information provided in a number of languages for each and every clinical trial where there is the potential to recruit a subject for whom English is at best a second language. It seems unreasonable to expect every research team to produce information in all languages spoken in multicultural Britain and if necessary to provide it on an audiocassette where there is a chance that the subject may not be literate. Ethics committees could argue that in multicentre or large clinical trials the government or multinational pharmaceutical companies may have the resources to deal with this issue. In reality the process of planning and executing research would be considerably retarded by adherence to such a counsel of perfection in every single study.

If the issue of recruitment from every section of our society is overlooked or fudged there is a real danger that the results of research may harm patients or that the process of conducting research will be seen as riding roughshod over the rights of a minority of patients, subjects of this country. National Health Service patients in the UK can, potentially, be invited to participate in medical research. It could be said that patients who are excluded from such recruitment without very good reason are being denied the full experience of life as a member of our society. This may add to any sense of isolation.

Researchers have suggested that occasionally relatives or local translators could be employed to translate information sheets verbally. However, the possibility that such translators may persuade rather than inform remains a concern and ethics committees may be uneasy about such a proposal when the accuracy of the translation cannot be judged on a written record. Finally it is a matter for those who read and act on the findings of research to ensure that results are generalisable to all their patients. Therefore it is in the interests of researchers to clarify which groups of patients have been recruited and to specify which groups have been excluded and why.

\section{References}

1 Larson E. Exclusion of certain groups from clinical research. Image - the four nal of Nursing Scholarship 1994;26,3:185-90.

DR MOYEZ JIWA

Lecturer in General Practice, Institute of General Practice,

University of Sheffield

\section{Medicine and literature: imagine a third way}

SIR

I have followed with interest the editorial by $\mathrm{R}$ Gillon, Imagination, literature, medical ethics and medical practice ${ }^{1}$ and $\mathrm{N}$ Pickering's rebutting article, Imaginary restrictions. ${ }^{2}$ In short the former praises the use of literature in medical practice and medical education: "Literature can illuminate our interpretation of our patients' stories; their stories and their interpretation can illuminate both medical science and philosophical medical ethics". Pickering argues-in a more difficult to understand paperthat such a position "restricts the role of the imagination in medical ethics by putting forward an instrumentalist account of the role of literature in ethical reflection". These differences remind me of an anecdote of the
Argentine writer, Jorge Luis Borges. His opponent-in the field of literature as well as politics-was the Chilean Nobel Prizewinner, Pablo Neruda. A very peculiar situation arose over the years because every time Borges was asked about his colleague he would praise, even glorify, him. On the other hand, in similar situations Neruda invariably undervalued Borges. Finally a reporter asked the Argentinian about this whole matter: was he right or was Neruda right? Borges gave a short answer: "Probably both of us were wrong".

From the point of view of a doctor currently using medicine and literature in medical education, the arguing above, of both Gillon and Pickering and Borges and Neruda, is at least difficult to understand and definitely beyond the interests of medical practice. Moreover, it is even disappointing. The days of the so called "Flexner-Osler debate", the controversy between scientific and humanistic medical education, are not gone. Many of us are elbowing our way towards the introduction of humanistic disciplines into the curricula of medical schools. It does not seem fair to jeopardise what has been achieved in this field over the years by crossfired arguments which a physician cannot even imagine being related to his/her daily practice.

With regards to both sets of persons to whom I have alluded, whom I do not know personally, allow me, finally, to quote Shakespeare:

"If we do meete [again], why we shall smile,

If not, why then this parting was well made".

\section{References}

1 Gillon R. Imagination, literature, medical ethics and medical practice. Fournal of Medical Ethics 1997;23:3-4.

2 Pickering N. Imaginary restrictions. fournal of Medical Ethics 1998;24:171-

DR L ACUÑA MD, PHD Chairman of Medical Humanities, School of Medicine, National University of La Plata, Republica Argentina, Calle 60 y 120 La Plata (1900) E-mail:solmayor@netverk.com.ar 